\title{
O VIDEODOCUMENTÁRIO COMO REGISTRO DOS 30 ANOS DE TRABALHO DA LUMEN ET FIDES NO ATENDIMENTO DA PESSOA COM DEFICIÊNCIA
}

Weverson Junior Santos do Nascimento ${ }^{1}$, Thaisa Sallum Bacco ${ }^{2}$, Wesley Carlos Marcelino Murici ${ }^{3}$, Rafaela Silva Garbal ${ }^{4}$, Shorrayla Indayara Duda Attar ${ }^{4}$

${ }^{1}$ Especializando em Artes Visuais pela Universidade Estadual de Maringá - UEM, Maringá, PR. Graduado em Comunicação Social - Jornalismo pela Universidade do Oeste Paulista - UNOESTE, Presidente Prudente, SP. E-mail: weverson_junyor@hotmail.com.

${ }^{2}$ Doutora em Educação pela Universidade Estadual Paulista - UNESP, Presidente Prudente, SP. Professora da Faculdade de Comunicação Social da Universidade do Oeste Paulista - UNOESTE, Presidente Prudente, SP.

${ }^{3}$ Graduado em Comunicação Social - Jornalismo pela Universidade do Oeste Paulista - UNOESTE, Presidente Prudente, SP.

${ }^{4}$ Graduanda em Comunicação Social - Jornalismo pela Universidade do Oeste Paulista - UNOESTE, Presidente Prudente, SP.

\section{RESUMO}

A presente pesquisa teve o objetivo de documentar o trabalho da Associação de Desenvolvimento de Crianças Limitadas - Lumen et Fides, que há 30 anos oferece tratamento na área de saúde e educação, atendendo crianças e adultos com deficiências múltiplas e transtorno do espectro do autismo em habilitação. Leva ao conhecimento da sociedade, por meio de um videodocumentário, a existência dos atendimentos oferecidos e como a instituição pode contribuir na vida da pessoa com deficiência. $O$ estudo utilizou a abordagem qualitativa e, como método, o estudo de caso. Os instrumentos de coleta de dados foram: pesquisa bibliográfica, pesquisa de campo com entrevistas em profundidade através de roteiro semiaberto e pesquisa e análise documental. A análise dos dados foi feita por meio da técnica de triangulação para documentar o trabalho realizado pela instituição. Todas as informações coletadas serviram como base para composição do videodocumentário "Sonhos de Maio", com duração de 67 minutos, que por meio do jornalismo humanizado divulga para sociedade as contribuições da instituição na vida da pessoa com deficiência.

Palavras-chave: Videodocumentário. Lumen et Fides. Jornalismo humanizado. Presidente Prudente.

\section{THE VIDEO DOCUMENTARY AS A RECORD OF THE 30 YEARS OF WORK OF LUMEN ET FIDES ON THE ATTENDANCE OF THE DISABLED PERSON}

\begin{abstract}
The present research had as a goal to document the work of the Development Association of the Limited Children - Lumen et Fides which has offered for 30 years the treatment in the health and education fields helping children and adults with multiple deficiencies and disorder of the spectrum of the autism in the habilitation process. The research intends to take to the society's knowledge through a video documentary, the existence of the attendances offered and how the institution is able to contribute in the life of the deficient person. This study used the qualitative approach and as a method the study of case. The data collecting instruments were: bibliographic research, field research with deep interviews through a semi open script and documental research and analysis. The analysis of the data was done through the triangulation technique to document the work done by the institution. All the collected information served as a basis for the composition of the theoretical cut and also of the practical play entitled - Dreams of May, with duration of 67 minutes, leading through humanized journalism discloses to society the contributions of the institution in the life of the disabled person.
\end{abstract}

Keywords: Video documentary. Lumen et Fides. Humanized Journalism. Presidente Prudente. 


\section{INTRODUÇÃO}

No mundo existem diversos tipos de deficiências. Segundo o Ministério da Saúde (BRASIL, 2010), as principais causas das deficiências são hereditárias ou congênitas, pois são decorrentes da falta de assistência adequada às mulheres durante a gestação ou parto.

De acordo com a última publicação do censo demográfico do Instituto Brasileiro de Geografia e Estatística (INSTITUTO BRASILEIRO DE GEOGRAFIA E ESTATÍSTICA, 2010), no Brasil, 45.606.048 milhões de pessoas declararam ter pelo menos uma das deficiências, o que corresponde a $23,9 \%$ da população brasileira.

Em Presidente Prudente, o último levantamento feito pelo Instituto Brasileiro de Geografia e Estatística (2010) apontou que 43.936 pessoas possuem pelo menos uma das deficiências investigadas: visual, auditiva, motora, mental ou intelectual. O inciso IV do artigo 203 da Constituição Federal (BRASIL, 1988) garante a esse público a habilitação e reabilitação e a promoção de sua integração à vida comunitária. No município, existem 58 entidades de assistência social e de saúde, classificadas sem fins lucrativos (INSTITUTO BRASILEIRO DE GEOGRAFIA E ESTATÍ́STICA, 2010). De acordo com a Coordenadoria Municipal dos Direitos da Pessoa com Deficiência em Presidente Prudente, há oito entidades assistenciais filantrópicas que tratam da pessoa com deficiência.

Uma dessas entidades é o objeto de estudo deste estudo: a Associação de Desenvolvimento de Crianças Limitadas - Lumen et Fides, que atende às deficiências classificadas como neuromotoras e neuromusculares, consideradas deficiências físicas e também conhecidas como limitações múltiplas. Em Presidente Prudente, a limitação física, segundo o Instituto Brasileiro de Geografia e Estatística (2010), apresenta 15.993 casos. A instituição Lumen também habilita a pessoa com transtorno do espectro do autismo (TEA), considerado deficiência intelectual.

Caracterizada como instituição filantrópica, a Lumen foi fundada em 15 de maio de 1987, por um grupo de pais com filhos deficientes. Eles tinham como objetivo melhorar a funcionalidade e independência de seus filhos, assim como socializá-los (LUMEM ET FIDES, 2012, p.6). Desde sua fundação, a entidade conta com profissionais multidisciplinares e especializados em atividades que estimulam a percepção de crianças e adultos limitados.
A escolha da instituição para esta pesquisa foi motivada por oferecer continuidade do tratamento oferecido independentemente da idade ou condição física, psíquica e motora do assistido. Também por possuir tratamento de equoterapia (considerado o primeiro centro do Brasil dentro de uma instituição), sala de estímulos multissensoriais pioneira na cidade, bem como realizar atendimentos aos pacientes com transtorno do espectro do autismo em Presidente Prudente.

Os pesquisadores propõem documentar a importância da Lumen et Fides no trabalho e tratamento na vida de deficientes ao longo dos últimos 30 anos e com propósito de continuidade.

A relevância social da pesquisa está em disseminar informações sobre a Lumen et Fides, que contribui com atendimentos voltados à saúde e à educação da pessoa com deficiência e assim revelar, a partir de um videodocumentário, o papel da instituição para as famílias que possuem pessoa com deficiência e para estudantes e profissionais das áreas de atuação (saúde e educação).

Em termos acadêmicos, a investigação mostra-se relevante, pois aprofunda o uso do jornalismo como instrumento de registro histórico, documentando o trabalho realizado por uma instituição que proporciona a habilitação de pessoas com deficiência física e intelectual.

Em âmbito pessoal, a pesquisa vem ao encontro da afinidade com a linguagem audiovisual (aprimorada em estágio na TV Facopp Online) e o desafio de levar informações, esclarecimentos, histórias, a partir do jornalismo humanizado retratado por meio de videodocumentário.

Assim, como problemática desta pesquisa, coloca-se o seguinte questionamento: como a Lumen et Fides se desenvolveu durante três décadas no atendimento de deficientes com limitações neuromotoras, neuromusculares e transtorno do espectro do autismo?

Em busca de respostas ao problema da pesquisa, traçou-se como objetivo geral documentar as contribuições da Lumen et Fides no atendimento a deficientes com limitações múltiplas e transtorno do espectro do autismo ao longo de 30 anos de história. E como objetivos específicos, tem-se: compreender o processo de produção de um documentário em vídeo; traçar um panorama histórico com os principais fatos ocorridos nos 30 anos de atendimento da Lumen 
et Fides nas áreas de saúde e educação; vivenciar a prática do jornalismo humanizado promovendo as visões dos atendidos, profissionais, fundadores e aqueles que contribuíram com a história da Lumen; retratar, por meio de videodocumentário, as atividades desenvolvidas pela Lumen no atendimento a deficientes com limitações múltiplas e transtorno do espectro do autismo.

\section{METODOLOGIA}

Para executar este trabalho, a natureza da pesquisa é qualitativa, na qual a relação entre o mundo e o sujeito não pode ser traduzida em números. De acordo com Gil (2012, p. 27), é uma pesquisa desenvolvida com o objetivo de proporcionar visão geral de tipo aproximativo, acerca de determinado fato "[...] é realizada especialmente quando o tema escolhido é pouco explorado e torna-se difícil sobre ele formular hipóteses precisas e operacionais."

Como método, foi utilizado o estudo de caso, que permitiu aos pesquisadores conhecerem a Lumen et Fides de forma aprofundada.

Para Yin (2010, p. 24), o método do estudo de caso permite que o investigador retenha as características abrangentes e significativas dos eventos da vida real, isto é, os ciclos individuais da vida, comportamentos de pequenos grupos e até mesmo desempenho escolar. Deste ponto de vista, é relevante mencionar que neste estudo, o método auxiliou na escolha das pessoas com deficiência e suas histórias, posteriormente contadas por familiares.

O autor ainda defende que a relevância do estudo de caso parte da necessidade e desejo de compreender fenômenos sociais complexos. "[...] o estudo de caso é usado em muitas situações, para contribuir com o nosso conhecimento dos fenômenos individuais, grupais, organizacionais, sociais, políticos e relacionados." (YIN, 2010, p. 24). Considera-se, a este respeito, que a utilização do método proporcionou aos pesquisadores compreender 0 processo histórico da Lumen et Fides e sua contribuição na vida da pessoa com deficiência através de relatos de profissionais, fundadores e aqueles que contribuíram com a história da instituição.

A partir da escolha da natureza e do método faz-se necessário a seleção de instrumentos de coleta de dados que, segundo Lakatos e Marconi (2010, p. 163), estão diretamente relacionados com o problema a ser estudado. "[...] a natureza dos fenômenos, o objeto da pesquisa, os recursos financeiros, a equipe humana e outros elementos que possam surgir no campo da investigação."

Os instrumentos para coleta de dados utilizados neste estudo dividiram-se em pesquisa bibliográfica, pesquisa de campo com entrevistas em profundidade do tipo semiaberta e pesquisa e análise documental. Como ponto de partida, a pesquisa bibliográfica foi realizada para embasamento teórico sobre os temas deficiência e documentário.

De acordo com Lakatos e Marconi (2010, p. 166), a pesquisa bibliográfica tem o objetivo de colocar o pesquisador em contato direto com o tema a ser estudado, "[...] com tudo o que foi escrito, dito ou filmado sobre determinado assunto." Os pesquisadores buscaram informações em livros, artigos científicos e revistas, totalizando 80 leituras e fichamentos de referenciais teóricos disponíveis na biblioteca da Universidade do Oeste Paulista (Unoeste) e também em outras bibliotecas virtuais.

A pesquisa de campo foi utilizada para obter informações sobre o objeto de estudo e conhecer melhor os atendidos pela Lumen. Lakatos e Marconi (2010, p. 169) definem que a pesquisa de campo é utilizada com o objetivo de conseguir informações ou conhecimentos acerca de um problema, "[...] para o qual se procura uma resposta, ou de uma hipótese, que se queira comprovar, ou, ainda, de descobrir novos fenômenos ou as relações entre eles." Os pesquisadores estiveram a campo, convivendo na Lumen, durante 15 dias e observaram o trabalho desenvolvido pela instituição, levantando informações através de pré-entrevistas sobre o desenvolvimento histórico dos 30 anos, os atendimentos nas áreas de saúde e educação e busca por personagens que iriam compor o videodocumentário.

A pesquisa de campo tornou-se fundamental também para levantar os nomes das fontes que seriam entrevistadas em profundidade. Para Duarte $(2009$, p. 64), a entrevista em profundidade é uma técnica dinâmica e flexível, "[...] útil para apreensão de uma realidade tanto para tratar de questões relacionadas ao íntimo do entrevistado, como para descrição de processos complexos nos quais está ou esteve envolvido."

Ainda segundo Duarte (2009, p. 64), entrevistas em profundidade podem ser divididas 
em dois tipos: a aberta e semiaberta. A utilizada pelo grupo foi a entrevista semiaberta, que partiu de um roteiro possível de ser alterado no decorrer da entrevista, sendo adaptável, permitindo flexibilidade: "[...] o pesquisador faz a primeira pergunta e explora ao máximo cada resposta até esgotar a questão. Somente então passa para a segunda pergunta." (DUARTE, 2009, p. 66). Nesta pesquisa, foram selecionadas 27 fontes para darem entrevista. O critério de seleção foi a busca por profissionais de todas as áreas do atendimento da Lumen, bem como famílias que representam as diferentes realidades trabalhadas pela instituição.

Outra técnica para coleta de dados foi a pesquisa e análise documental utilizada para acompanhar a evolução da Lumen ao longo dos 30 anos, em material disponível pela instituição. Para Gil (2012, p. 51), a análise documental pode ser utilizada como técnica quando "[...] a pesquisa documental vale-se de materiais que não receberam ainda um tratamento analítico, ou que ainda podem ser reelaborados de acordo com objetivos da pesquisa."

Durante a pesquisa, o grupo levantou documentos como atas de reuniões, estatutos, decretos de utilidades públicas (Federal, Estadual e Municipal), atestados de entidade beneficente de assistência social e certidões de pessoa jurídica. Além desses materiais, o grupo obteve fotos e vídeos que mostram o desenvolvimento da instituição desde sua fundação até os dias de atuais e fotos pessoais, solicitadas às famílias da pessoa com deficiência, de forma a ilustrar o audiovisual.

A análise dos resultados foi realizada pela técnica da triangulação dos dados coletados. Para Triviños (1987, p. 138), este tipo de análise busca abranger máxima descrição, explicação e compreensão do foco em estudo: "Parte de princípios que sustentam que é impossível conceber a existência isolada de um fenômeno social, sem raízes históricas, sem significados culturais e sem vinculações estreitas e essenciais como uma macrorrealidade social."

Neste estudo, os dados obtidos durante a pesquisa de campo, de entrevistas e a pesquisa e análise documental foram cruzados e analisados, a fim de alcançar a resposta que motivou a pesquisa, ou seja, quais as contribuições da Lumen et Fides no atendimento de deficientes com limitações múltiplas e transtorno do espectro do autismo.

\section{REVISÃO DE LITERATURA}

\subsection{Documentário}

A constituição da linguagem cinematográfica deve seus conceitos às antigas formas de enquadramento do olhar, relacionadas à perspectiva renascentista como interpretadas por Hegemeyer (2012, p. 66):

Foi a partir do
Renascimento que
surgiram as formas
modernas de produção e
comercialização de
'quadros', com o
surgimento da 'tela' como
espaço privilegiado de
composição das formas do
mundo, onde os artistas
adotaram as metáforas
teatrais da 'cena' e do
'cenário' para ambientar
as 'ações' e os
'personagens retratados'.
A 'cena' passou a ser
dividida em diferentes
'planos', e muitas vezes a
paisagem no qual o
retrato era produzido não
passava de um 'pano de
fundo', um simulacro de
paisagem produzido pelo
artista juntamente para
esse fim.

A constituição do olhar cinematográfico, para Hegemeyer (2012, p. 72), se relacionou com a busca pela multiplicação do olhar do indivíduo, seja através de ampliação graças a instrumentos óticos ou através do registro e da reprodução.

A revolução industrial no século XVIII foi um marco de novos inventos que permitiram aprender uma nova forma de captar imagens, olhar, através da inversão da câmara escura. "A fotografia se tornou a lente da verdade capaz de capturar uma imagem no fragmento do mundo, a partir de meios unicamente mecânicos." (HEGEMEYER, 2012, p. 74)

Para Hegemeyer (2012, p. 78), ao dar vida às imagens fotográficas, se estabelece uma leitura sequencial através da qual o espectador observa a relação de causa e efeito. Com a invenção do cinema, houve o aprimoramento das fotos em sequências, isto é, os mecanismos de projeção e desenvolvimento de padrões de linguagem e constituição de uma narrativa.

Para Mascelli (2010 p. 101), um filme é composto de vários planos, filmados de ângulos 
de câmera diferentes e agrupados numa sequência, ou seja, uma série de planos que se torna um capítulo da história, que, por sua vez, são combinadas para formar uma narrativa completa.

Antoniutti, Fontoura e Alvez (2008, p. 20) ressaltam que o processo de produção visual tem como finalidade principal comunicar algo a alguém através de métodos, técnicas e ferramentas de linguagens de forma intencional.

Para os autores (ANTONIUTTI; FONTOURA; ALVEZ 2008, p. 14), os seres humanos estão impregnados por signos e mensagens transmitidas por meio de imagens e sons, para compreender sua percepção de mundo hoje, é necessário penetrar no universo da linguagem audiovisual.

Considera-se, a este respeito, a junção de elementos de duas naturezas: os sonoros e os visuais. Para Martin (2005, p. 28), a imagem é, antes de tudo, realista, dotada de todas as aparências da realidade. $\mathrm{O}$ som é igualmente um elemento decisivo da imagem pela dimensão que acrescenta ao restituir-lhe o ambiente dos seres e das coisas que sentimos na vida real. Essa junção prende o olhar na sua totalidade e o receptor passa a observar de forma atenta:

$\begin{array}{lr}\text { [...] o nosso } & \begin{array}{r}\text { campo } \\ \text { abrange }\end{array} \\ \text { auditivo } & \\ \text { constantemente } & \text { a } \\ \text { totalidade do espaço } \\ \text { ambiente, enquanto que o } \\ \text { nosso olhar apenas } \\ \text { consegue abranger de } \\ \text { uma só vez um ângulo de } \\ \text { sessenta graus, e por } \\ \text { vezes de trinta se } \\ \text { pretender observar de } \\ \text { maneira atenta. (MARTIN, } \\ \text { 2005, p. 28) }\end{array}$

Ainda segundo Martin (2005, p. 28), o que distingue o cinema de todos os outros meios de expressão cultural, é o poder excepcional que resulta do fato de sua linguagem funcionar a partir da reprodução fotográfica da realidade, ou seja, são os próprios seres e as próprias coisas que aparecem e falam.

Para Puccini (2007), no documentário, o controle do universo de representação trata-se de uma aquisição gradual, um processo de troca entre um "eu" e um "outro". "O percurso é marcado pela perspectiva daquilo que está por vir, a captura de um real que gradualmente vai sendo moldado até se transformar em filme." (PUCCINI, 2007, p. 21)

Dentro desta concepção, está a construção de um discurso, que segundo o autor, é sedimentado em ocorrências do real. "Se existe um discurso, o filme, quer seja ele narrativo ou não, existirá sempre alguém que o profere, um sujeito da enunciação." (PUCCINI, 2007, p. 21).

A composição das cenas, para Puccini (2007), está ligada à relação palavra-imagem, embora uma peça audiovisual não se resuma apenas ao conteúdo das suas imagens.

É na descrição de imagens que se encontra o maior desafio para o roteirista. De fato, o roteiro, para ser cinematográfico, deve se ater apenas àquilo que está ao alcance do olhar, seu texto tem necessariamente de estar submetido a essa condição de descrever sempre alguma coisa que é dada a ver. (PUCCINI, 2007, p. 31)

Este estudo parte da concepção, feita por Puccini (2007 p. 32), de que é na descrição de situações vivenciadas por personagens que se encontra o campo de total domínio para aquele que se utiliza da palavra para pensar o filme, assim, o discurso levará a pessoa a refletir sobre os relatos da história dos personagens. Diante disso, busca-se não apenas a estética da imagem, mas estimular pensamentos ou reflexões sobre o tratamento oferecido pela instituição à pessoa com deficiência.

Para o autor (2007, p. 39), quando se trata da característica de ser um discurso de filme documental, pode ser sustentado por ocorrências do real:

Trata efetivamente
daquilo que aconteceu,
antes ou durante as
filmagens, e não daquilo
que poderia ter
acontecido como no caso
do discurso narrativo
ficcional. Essa ancoragem
no real vai encontrar seus
procedimentos chave
sempre na busca de sua
legitimação (PUCCINI,
2007, p. 39)

Para Puccini (2007, p. 100), a exploração do recurso da entrevista, como principal ponto 
de sustentação da estrutura discursiva do filme, vem a ser uma das características do documentário. Pode-se dizer que a entrevista está para o documentário assim como a encenação está para o filme de ficção.

Esse momento da
entrevista constrói um
personagem que se revela
na interação com o
entrevistador (muitas
vezes o próprio diretor do
filme); não em situação de
ação, mas através de uma
exposição oral que pode
descrever ações de uma
narrativa ou simplesmente
exteriorizar comentários.
O relato de ações ou os
comentários podem trazer
embutido a referência a
outros personagens,
chegando mesmo a
minimizar o papel do
entrevistado colocando-o
mais na condição de
testemunha de um
determinado evento
histórico. (PUcClNI, 2007,
p. 100)

$\mathrm{Na}$ produção do videodocumentário "Sonhos de Maio" a técnica da entrevista teve como sustentação a prática do jornalismo humanizado.

\subsection{Jornalismo Humanizado}

O jornalismo não é cinema, mas pode ser jornalismo realizado em audiovisual. "Na trajetória das mídias, o uso do cinema e do vídeo para fazer jornalismo nunca foi desprezado [...]." (TAVARES, 2005, p. 12)

O documentário utiliza-se do jornalismo através de técnicas e estruturas que nesta pesquisa foram analisadas a partir do jornalismo humanizado.

No que diz respeito a jornalismo e documentário, Silva $(2006$, p. 77 ) lista elementos e argumentos que unem, mas também separam as duas atividades.

As distinções e
semelhanças gravitam em
torno de questões
relacionadas à autoria,
criatividade, objetividade,
$\begin{array}{lr}\text { unidade temporal, } \\ \text { efemeridade } \\ \text { profundidade, versus } \\ \text { suporte }\end{array}$

tecnológico e industrial (cinema e televisão), presença ou ausência de narradores, rotinas de produção,

comprometimento com a ética, tema e expectativas da recepção, para citar algumas mais recorrentes. (SILVA, 2006, p. 77)

Segundo Silva (2006, p. 79), documentário e reportagem não são a mesma coisa, mas há uma diversidade de modos de documentários, assim como há diferentes formas de construir reportagem.

O jornalismo como um ato de comunicação surgiu exatamente pela capacidade dos humanos de criar sistemas que thes permitam compartilhar informações, pensamentos e ideias, o que faz do fazer jornalístico uma ação humana (IJUIM, 2011, p. 3).

Alves e Sebrian (2008, p. 1) referem-se ao processo de significação que exige observação, percepção, reflexão e expressão de mundo a qual os jornalistas devem ir além do dar a notícia para compreender os fenômenos sociais e compartilhar esta compreensão. A evidencia apresentada pelos autores $(2008$, p. 1 ) se estende ao definir também que o jornalismo humanizado não propõe apenas produzir textos diferenciados que valorizam personagens, mas se trata de um olhar, uma perspectiva, um ponto de partida diferenciado.

Ainda segundo Alves e Sebrian (2008, p. 1), o jornalismo humanizado dispõe fomentar a recuperação do prazer e do desejo de descobrir as pessoas no contexto social em que vivem, no qual a narrativa tem uma marca autoral inovadora. Isso significa humanizar as técnicas profissionais em prol da vitalidade do cotidiano, uma vez que a gramática jornalística atual não dá conta das demandas coletivas.

Alvez e Sebrian (2008, p. 8) afirmam que o jornalista não se relaciona apenas com um objeto de conhecimento, mas também com outros seres humanos envolvidos no processo comunicativo:

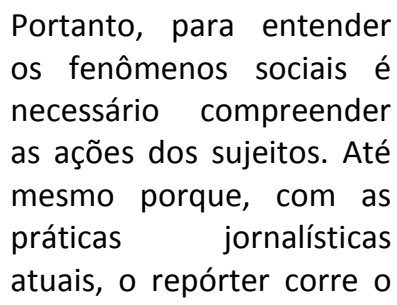


risco de concentrar-se somente nos fatos, desprezando as múltiplas conexões com os outros fatos e, portanto, a contextualização

necessária para a compreensão das ações que originaram a matéria e também da sociedade. (ALVES; SEBRIAN, 2008, p. 8).

Deste ponto de vista é relevante mencionar que segundo os autores (ALVES; SEBRIAN , 2008, p. 8), o relato das ações humanas e a compreensão dos sentidos dos fenômenos são 0 resultado da observação/percepção e, ao mesmo tempo, da reflexão dos fenômenos; acontece quando os jornalistas vão às ruas à procura das experiências a fim de resgatar as histórias dos protagonistas sociais.

O relato jornalístico humanizado, para Montipó (2011, p. 4-5), é aquele que não busca disseminar preconceitos, mas compartilhar sentidos e valores universais.

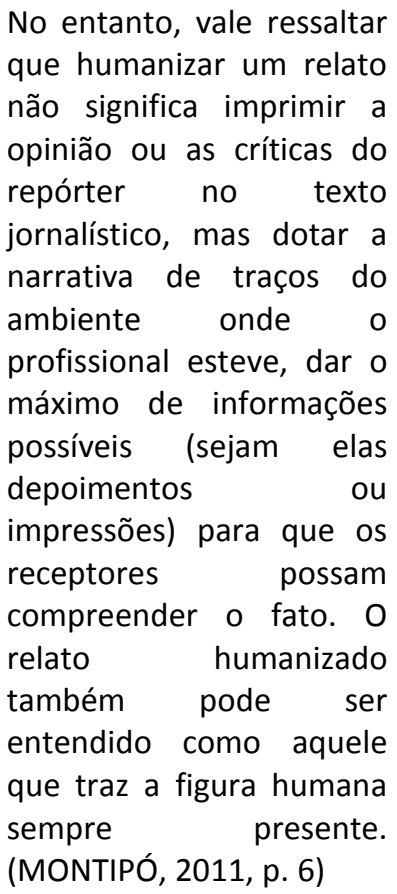

O autor (MONTIPÓ, 2011, p. 7) reforça que nesses casos humanizados é importante o repórter estar atento aos valores universais contidos na singularidade humana, e tomem cuidado para não criar estereótipos. Nesta pesquisa, ao abordar a deficiência neuromotora, neuromuscular e o transtorno do espectro do autismo, os pesquisadores sempre buscaram não diagnosticar a pessoa com deficiência sem antes compreender, por relatos e testemunho de profissionais das áreas da saúde e educação, as reais condições da pessoa com deficiência.

Para Ijuim (2011, p. 14), o jornalismo humanizado produz narrativas em que o ser humano é o ponto de partida e de chegada, e supõe que se inicia antes da pauta, na consciência do ser jornalista.

No trabalho de apuração, busca versões verdadeiras e não, necessariamente, produz a verdade, pois o repórter não se relaciona com um objeto, mas com outros seres humanos envolvidos no processo comunicativo. Dessa forma, sua busca envolve a compreensão das ações dos sujeitos da comunicação - é a expressão dos sentidos da consciência. Na procura da essência dos fenômenos, atribui-Ihe significados, os sentidos, para proporcionar ao público, mais que a explicação, a compreensão das ações humanas. (IJUIM, 2011, p. 133)

Já Alves e Sebrian (2008) afirmam que o jornalismo humanizado busca compreender os fenômenos e não pode se limitar apenas à factualidade das notícias. E foi com base neste pensamento que houve a aproximação do objeto de estudo.

\subsection{Lumen et Fides}

A Associação de Desenvolvimento de Crianças Limitadas - Lumen et Fides foi fundada em 15 de maio de 1987 pelo seguinte grupo: Ademar Barreto Nobre, Andréo Kozuki, Aparecida Mieko Sawamura Kozuki, Argene Maria Virgili Lemos, Carlos Alberto Santos, Clara Aparecida Bongiovani, Edmundo Werner Roll, José Demétrio Pontalti, Manoel Francisco Lemos, Ricardo Cesar Miele e Vera Ines Valente dos Santos. Eles buscavam tratamentos adequados para os filhos com características de autismo e com problemas neurológicos e assemelhados.

Para formar o nome da Associação, o grupo de fundadores utilizou de três palavras a relacionar seus significados à sua missão. 
A palavra Lúmen é 0 mesmo que uma unidade de fluxo luminoso e foi escolhida para representar a luz que brilha indicando o caminho do bem. Já a palavra Fides, que vem do Latim, significa fiel, e representa o laço de amizade que une os homens que se propõem a realizar algo bom. Desta forma, Lumen Et Fides, significa Luz e Fé. (LUMEN ET FIDES, 2012, p. 11, grifo do autor)

Em sua primeira ata de reunião no dia 23 de março de 1987, o principal objetivo definido pelo grupo de pais foi a criação de uma escola sem preocupação de diagnóstico de cada aluno e que uma vez criada atenderia crianças de Presidente Prudente e região.

$\mathrm{Na}$ mesma ocasião foi determinado o primeiro corpo de diretoria e conselho fiscal, que ficou frente da Lumen de 16 de maio de 1987 até 15 de maio de 1989. Conforme prevê o Art. 22 do Estatuto da Associação de Desenvolvimento De Crianças Limitadas - Lumen et Fides (1987): “A Diretoria da Associação será eleita na 2a (Segunda) quinzena do mês de maio, sendo de 2 (dois) anos o seu mandato, com início em 16 de maio de 1987, permitida a reeleição de qualquer de seus membros."

Dando início aos trabalhos, os primeiros atendimentos ocorreram em uma chácara às margens da Rodovia Raposo Tavares (SP-501), no município de Álvares Machado (SP), que pertencia aos fundadores Manoel Francisco Lemos e Argene Maria Virgili Lemos, no dia 13 de maio de 1987. No mesmo ano, a Associação passou a funcionar no fundo da Igreja Presbiteriana Independente, localizada na Rua Siqueira Campus, 814, em Presidente Prudente, mas por motivos de espaços físicos passou oferecer seus atendimentos em outro local.

Em 1988, a instituição instalou-se na Avenida Coronel José Soares Marcondes, 905, bairro do Bosque. No mesmo ano, pela primeira vez, foi declarada de Utilidade Pública Municipal pela Câmara de Presidente Prudente (SP), com a Lei Municipal no 2.618/88. Segundo o Sindicato das Instituições Beneficentes Filantrópicas e Religiosas do Estado de São Paulo (SINDICATO DAS INSTITUIÇÕES BENEFICENTES
FILANTRÓPICAS E RELIGIOSAS DO ESTADO DE SÃO PAULO, [s.d.]), esta atribuição assegura às instituições o direito a isenção do Imposto Predial e Territorial Urbano (IPTU), Imposto Sobre Serviços (ISS), auxílio financeiro concedido pelo Poder Público local e isenção de tarifas públicas nos municípios onde esses serviços não foram privatizados (água e luz). Despesas que eram, até então, mantidas pelos fundadores.

No início da década de 1990, a Associação dos Pais e Amigos dos Excepcionais (Apae) de Presidente Prudente cedeu espaço em uma das alas para os atendimentos da Lumen. A instituição Lumen funcionava na rua David Cerqueira Leite, 261, porém, houve a necessidade de maiores ambientes devido ao crescimento no número de atendidos. (LUMEM ET FIDES, 2012, p. 11)

Em abril de 1991, a Lumen passou a funcionar no Serviço de Obras Sociais (SOS), na Rua José Tarifa Conde, 1023.

No mesmo ano ocorreu o início da implantação do considerado primeiro centro do Brasil de equoterapia dentro de uma instituição, após as fisioterapeutas Rosimeire Geraldo Peres, Agda Marcia dos Santos e Lucila Kato e juntamente com a fundadora Argene Maria Virgili Lemos, terem participado do 1을 Encontro Nacional de Equoterapia, em Brasília.

Acreditando na potencialidade do método, "[...] a instituição organizou-se para sua implantação, providenciando espaço físico adequado, adquirindo animais adestrados e a capacitação de sua equipe interdisciplinar." (LUMEM ET FIDES, 2012, p. 25) E, em 1992, foi definitivamente implantada.

No dia 3 de setembro de 1992, a entidade foi decretada de Utilidade Pública Federal pela Presidência da República, de acordo com o processo no 6.286/92-11. Para o Sindicato das Instituições Beneficentes Filantrópicas e Religiosas do Estado de São Paulo ([s.d.]), uma instituição enquadrada nesses parâmetros passa a ter benefícios como: certificado de fins filantrópicos junto ao Conselho Nacional de Assistência Social, isenção do recolhimento da quota patronal para o Instituto Nacional do Seguro Social (INSS), gozo das isenções das contribuições sociais, possibilidade de receber benefícios e subvenções da União e permitir às pessoas físicas e jurídicas a dedução no Imposto de Renda de doações em nome da entidade.

Em 1993, com o fechamento da instituição que atendia deficientes adultos, a 
Associação dos Deficientes Físicos Albert Sabin, a Lumen recebeu parte de sua atual sede própria, na Rua Maria Fernandes, 449, no Jardim Alto da Boa Vista, cedida pela Prefeitura Municipal de Presidente Prudente.

No dia 16 de maio de 1997, após a Lumen enfrentar novamente problemas financeiros, passou a ser administrada por sócios contribuidores da Loja Maçônica de Presidente Prudente, Cavaleiros Arte Real. No mesmo ano, foi criada sua primeira administração com integrantes da sociedade. A Lumen completa 30 anos em 2017 e atualmente atende 150 pessoas do município e região.

\section{PROCEDIMENTO}

Iniciou-se à pesquisa mediante aprovação do Comitê de Ética em Pesquisa sob o parecer 2431037, protocolo CAAE número 63508217.0.0000.5515 e autorização da Direção da instituição Lumen et Fides. A Coordenação Pedagógica na ocasião comunicou aos pais ou responsáveis verbalmente sobre a intervenção dos quatro pesquisadores na instituição.

Durante a imersão de 15 dias na instituição, os pesquisadores puderam compreender a importância das atividades que visam à habilitação de seus atendidos. Foram dias de observação e acompanhamento de profissionais em atividades, que proporcionaram demonstrar a funcionalidade e as necessidades terapêuticas, revelados no videodocumentário.

As observações realizadas na Programação 1 que atende crianças e adultos com deficiências múltiplas (neuromotora e neuromuscular) na área de saúde e educação, proporcionaram a compreenção de comportamentos, formas de comunicação, didática das professoras, ou seja, o método utilizado para a habilitação da pessoa com deficiência.

No Centro de Educação e Reabilitação (CER), ala onde são atendidas crianças com transtorno do espectro do autismo. As observações foram autorizadas em apenas três salas de aulas devido à alteração de comportamento de algumas crianças, característica da pessoa com autismo. Na ocasião foi realizado o mesmo processo anterior: comportamentos e forma de comunicação das crianças e didática das professoras.

Os pesquisadores buscaram conhecer também os atendimentos de saúde: fonoaudiologia, fisioterapia, terapia ocupacional, psicologia, serviço social, nutrição, enfermagem e atendimento médico. Além das terapias complementares: equoterapia, hidroterapia e integração sensorial. Para o grupo, a pesquisa de campo foi de extrema importância para conhecer os atendimentos da instituição e os personagens que fizeram parte do documentário.

As setes histórias de pessoas com deficiências retratadas em Sonhos de Maio (Gabriele Tavares, Enzo Ferraz, Jessé Ferraz Lorenzo Alves, Bruno Chiantaretto, Rafael Honório e Manuela Miranda) foram selecionadas a fim de retratar famílias que representassem as diferentes realidades trabalhadas pela instituição, trazendo também o relato humanizado de quem tem ou convive com a deficiência.

Para Souza (2007), o documentário não é apenas o lugar onde o depoente "ganha o direito de voz", mas permite apresentar ao espectador diversas vozes para que ele possa construir seu próprio ponto de vista ou conclusão.

\section{CONSIDERAÇÕES FINAIS}

A proteção e a integração da pessoa com deficiência na sociedade estabelecem-se no Brasil desde a Constituição Federal de 1988, no Art. 24 inciso XIV. (BRASIL, 1988) Porém, em uma sociedade que ainda no século XXI dita seus padrões de normalidade, a deficiência seja ela congênita, hereditária ou consequência de doenças, traumas ou lesões, torna-se pouco compreendida até que afete lares ou famílias das reais necessidades de uma pessoa com deficiência.

Presidente Prudente, segundo o Instituto Brasileiro de Geografia e Estatística (2012), conta com uma população de 207.610 pessoas, dessas, 43.936 são pessoas com deficiências que têm necessidade de atendimentos e, assim, de órgãos e instituições para a habilitação ou reabilitação. Uma delas é a Associação de Desenvolvimento de Crianças Limitadas - Lumen et Fides.

A presente pesquisa, cujos resultados são revelados no videodocumentário intitulado "Sonhos de Maio" (TV FACCOP ONLINE, 2017), buscou documentar as contribuições da Lumen et Fides no atendimento a deficientes com limitações múltiplas e transtorno do espectro do autismo ao longo de 30 anos de sua história. Em relação aos objetos específicos desta pesquisa, todos foram alcançados.

O primeiro foi o de compreender o processo de produção de um documentário em 
vídeo, que deve seguir as etapas de préprodução, produção e, por fim, pós-produção.

$O$ segundo objetivo foi traçar um panorama histórico com os principais fatos ocorridos nos 30 anos de atendimento da Lumen et Fides nas áreas de saúde e educação. Em relação à saúde, os pesquisadores compreenderam a busca incessante por parte da instituição em proporcionar métodos inovadores ao se tratar das limitações múltiplas e transtorno do espectro do autismo, sempre à procura da multidisciplinariedade e a necessidade do trabalho conjunto de diversas áreas para habilitação da pessoa com deficiência.

Seus tratamentos pioneiros, na década de 1990, trouxeram a Presidente Prudente recursos antes não vistos na região. No caso da equoterapia, técnica na qual a Lumen é pioneira no Brasil como centro dentro de uma instituição, desde sua instalação proporciona ao deficiente um atendimento especializado e diferenciado, sempre buscando o bem estar através de terapias complementares. (LUMEN ET FIDES, 2012, p.6) Atualmente, a instituição conta com o método do Pediasuit, o qual proporciona habilitação das deficiências múltiplas, considerado pelos profissionais como método eficaz e de mudanças significativas em postura e desenvolvimento do deficiente.

Os resultados dos atendimentos da Lumen são revelados no videodocumentário, a partir dos relatos de mães e profissionais que acompanham o desenvolvimento de cada assistido. O trabalho individual proporciona ao atendido diversos resultados por conter toda uma equipe envolvida com um só objetivo, habilitar a pessoa com deficiência.

No que se refere ao trabalho de educação da instituição, os pesquisadores perceberam que uma das contribuições da Lumen et Fides não é somente dentro das salas de aula ou também fora com a socialização da pessoa com deficiência, através de ações simples como realizar uma caminhada, ir a um supermercado, ou seja, estimular a funcionalidade e independência do indivíduo visto que muitas das vezes os pais ou responsáveis acabam por proteção, privando as do convívio social.

Compreendeu-se também que a entidade não contribui somente com seus assistidos, mas oferece apoio às famílias no que diz respeito à aceitação do diagnóstico e a manutenção deste ao longo dos anos. No contato dos pesquisadores com a instituição, foi possível identificar condições plurais de desenvolvimento de cada assistido. Puderam perceber também que a pessoa com deficiência tem uma vida social normal e que a sociedade deve integrar e não, apenas, incluir.

O terceiro objetivo foi o de vivenciar a prática do jornalismo humanizado promovendo as visões dos atendidos, profissionais, fundadores e aqueles que contribuíram com a história da Lumen. Esta ação proporcionou aos pesquisadores um contato em profundidade com testemunhos reais de famílias que têm a pessoa com deficiência, transmitindo em sensibilidade buscando não responder somente "o quê, quem, quando, onde, como e por quê" e sim o "e daí" das histórias. $O$ documentário trouxe questões de mundo que muitas vezes não são tratadas pela mídia, ou seja, são minimizadas como no caso das deficiências intelectuais. Colocou-se em discussão também o tema deficiência não somente como assunto a ser pautado, mas as condições de ouvir a pessoa com deficiência em situações comuns do dia a dia.

Uma contribuição geral deste trabalho foi a relação e contato com a pessoa com deficiência, visto que não fazia parte do cotidiano dos pesquisadores. Com o pouco conhecimento que se tinham sobre as limitações, muitas vezes chegaram com conceitos pré-estabelecidos sobre a deficiência física e deficiência intelectual e que no desenvolver da pesquisa foram quebrando barreiras.

Quanto aos sujeitos que contribuíram com a fundação da instituição, esta pesquisa mostrou as dificuldades no final da década de 80 para o acesso da pessoa com deficiência à rede de ensino em Presidente Prudente.

Atualmente, a instituição conta com atendimentos que visam o desenvolvimento e prestam apoio à pessoa com deficiência e suas famílias, pois compreendem que seus pacientes alcançam melhores resultados com uma estimulação contínua em casa.

E foi através destas necessidades que esta pesquisa chegou ao seu quarto objetivo específico, retratar por meio de videodocumentário, as atividades desenvolvidas pela Lumen no atendimento a deficientes com limitações múltiplas e transtorno do espectro do autismo. Durante a imersão de 15 dias na instituição, os pesquisadores puderam compreender a importância das atividades que visam à habilitação de seus atendidos. Foram dias de observação e acompanhamento de 
profissionais em atividades, que proporcionaram demonstrar a funcionalidade e as necessidades terapêuticas, revelados na peça prática.

Quanto à fundação e desenvolvimento da Lumen et Fides, os pesquisadores se sustentaram em relatos de quatro profissionais (João Baptista, Rosimeire Peres, Silvia Queiroz e Rosa Maria de Lima) que estão há mais de 20 anos na instituição, sempre buscando a construção dos fatos ocorridos ao longo dos 30 anos.

Ainda no processo de apuração, o contato durante 15 dias acompanhando salas de aulas e terapias complementares e alternativas, no que diz respeito a compreender o atendimento oferecido pela instituição à pessoa com deficiência, proporcionou também identificar personagens. No caso, foram selecionadas setes histórias de pessoas com deficiências retratadas em "Sonhos de Maio", a fim de apresentar famílias que representassem as diferentes realidades trabalhadas pela instituição, trazendo também o relato humanizado de quem tem ou convive com a deficiência.

No processo de produção, os conhecimentos adquiridos sobre documentário e construção da linguagem audiovisual, proporcionaram um delineamento da peça prática. Antes mesmo do início das gravações, uma das preocupações do grupo fazia referência em como abordar a pessoa com deficiência, no uso de terminologias. Nesta ocasião, realizaram estudos sobre a abordagem da mídia brasileira para com este público, a fim de identificar as melhores formas ao se referirem a pessoa na investigação do objeto de estudo, no contato com personagens e na forma a qual seria abordado no processo de produção em vídeo, tomando o cuidado de não inferiorizá-los.

$\mathrm{Na}$ produção, a importância da organização foi crucial para o desenvolvimento do projeto, com listas de entrevistados e macro e microtemas de assuntos a serem abordados. Durante duas semanas os pesquisadores gravaram 27 entrevistas, o que totalizaram $11 \mathrm{~h}$ brutas de material captado, na mesma ocasião, foram produzidos $14 \mathrm{~h} 35$ minutos de imagem.

No processo de pós-produção, as entrevistas transcritas foram cruciais para construção do roteiro de "Sonhos de Maio". Um processo desgastante para extrair do material bruto fragmentos importantes e o desafio da sequência dos personagens contar somente uma história. Em cada etapa de produção os pesquisadores exploravam os conhecimentos adquiridos teoricamente para que se chegasse ao resultado final desta pesquisa, revelado a partir de audiovisual.

Nesta mesma ocasião, os pesquisadores concluíram que o planejamento do videodocumentário foi fundamental para sua execução. E foi por meio das respostas dos objetivos específicos que esta pesquisa resolveu sua pergunta problema, como a Lumen et Fides se desenvolveu ao longo dos 30 anos no atendimento de deficientes com limitações neuromotoras, neuromusculares e transtorno do espectro do autismo.

É possível compreender que as ações dos pais fundadores não foram somente em contribuir com a melhora de seus filhos, mas o de oferecer a outras famílias as mesmas condições de atendimento. Todos os anos, novas parcerias são firmadas entre a instituição e as famílias para o desenvolvimento de crianças, adolescentes e adultos com deficiências. Mesmo com a passagem da administração de pais para sócios contribuintes, a Lumen sempre projetou oferecer atendimento a todos, investindo em infraestrutura, métodos e profissionais. A Lumen contribui também com a capacitação de seus funcionários através de cursos para melhoria no atendimento do transtorno do espectro do autismo e as deficiências múltiplas, buscando a raiz de sua formação, a união, o amor e o zelo. 0 que pode ser compreendido pela dedicação de cada profissional ao seu trabalho.

Uma vez que todos os objetivos foram cumpridos, a utilização do videodocumentário como registro dos 30 anos de trabalho da Lumen et Fides no atendimento da pessoa com deficiência, mostra o valor de uma instituição que oferece apoio a diversas famílias, o que muitas vezes não seria encontrado pelos pais. 0 documentário revela para sociedade um mundo real que precisa ser discutido e disseminado, ou seja, a importância da integração da pessoa com deficiência.

\section{REFERÊNCIAS}

ALVES, Fabiana Aline; SEBRIAN, Raphael Nunes Nicoletti. Jornalismo humanizado: O Ser Humano Como Ponto de Partida e de Chegada do Fazer Jornalístico. In: CONGRESSO DE CIÊNCIAS DA COMUNICAÇÃO NA REGIÃO SUL, 9., 2008. Guarapuava. Intercom - Sociedade Brasileira de Estudos Interdisciplinares da Comunicação. Guarapuava, 2008. Disponível em: 
$<$ http://www.intercom.org.br/papers/regionais/s ul2008/resumos/R10-0540-1.pdf>.

Acesso em: 5 jan. 2017.

ANTONIUTTI, Cleide Luciane; FONTOURA, Mara; ALVES, Marcia Nogueira. Mídia e produção audiovisual: uma introdução. Curitiba: Ibpex, 2008.

BRASIL. Constituição Federal (1988). Constituição da República Federativa do

Brasil. Brasília: Senado Federal, 1988. Disponível em:

<http://www.planalto.gov.br/ccivil_03/constituic ao/constituicaocompilado.htm>.

Acesso em: 14 set. 2016.

BRASIL. Ministério da Saúde. Política Nacional de saúde da pessoa com deficiência. Brasília:

Editora MS, 2010. Disponível em:

$<$ http://proacessi.com.br/arquivo/4dfce_Politica $\% 20$ Nacional\%20-

\%20Pessoa\%20com\%20Deficiencia.pdf $>$. Acesso em: 14 set. 2016.

DUARTE, Jorge. Entrevista em Profundidade. In: BARROS, Antonio; DUARTE, Jorge. Métodos e técnicas de pesquisa em comunicação. 2.ed. São Paulo: Atlas, 2009.

ESTATUTO DA ASSOCIAÇÃO DE

DESENVOLVIMENTO DE CRIANÇAS LIMITADAS Lumen et Fides, 1987.

GIL, Antonio Carlos. Métodos e técnicas de pesquisa social. 6. ed. São Paulo: Atlas, 2012.

HEGEMEYER, Rafael Rosa. História \& Audiovisual. Belo Horizonte: Autentica, 2012.

INSTITUTO BRASILEIRO DE GEOGRAFIA E ESTATÍSTICA - IBGE 2010. Cartilha do Censo

2010: Pessoa com Deficiência. Rio de Janeiro: IBGE, 2012. Disponível em:<http://www.pessoacomdeficiencia.gov.br/a $\mathrm{pp} /$ sites/default/files/publicacoes/cartilhacenso2010-pessoas-com-deficienciareduzido.pdf $>$.

Acesso em: 14 set. 2016

INSTITUTO BRASILEIRO DE GEOGRAFIA E ESTATÍSTICA - IBGE 2010. Censo demográfico

Presidente Prudente 2010. São Paulo, 2010.

Disponível em: <http://cod.ibge.gov.br/8ZUN>.
Acesso em: 26 out. 2016.

IJUIM, Jorge Kanehide. Humanização e desumanização no jornalismo: algumas saídas. In: CONGRESSO BRASILEIRO DE CIÊNCIAS DA COMUNICAÇÃO, 34., 2011. Recife. Intercom Sociedade Brasileira de Estudos Interdisciplinares da Comunicação. Recife, 2011. Disponível em:

$<$ http://www.intercom.org.br/papers/nacionais/ 2011/resumos/R6-2440-1.pdf>

Acesso em: 16 jan. 2017.

LAKATOS, Eva Maria; MARCONI, Marina de Andrade. Fundamentos de metodologia científica. 7. ed. São Paulo: Atlas, 2010.

LUMEN ET FIDES. 25 anos. Presidente Prudente: Prograf Projetos Gráficos, 2012.

Edição comemorativa Jubileu de Prata.

MASCELLI, Joseph. Os cinco Cs da

cinematografia: técnicas de filmagens. São Paulo: Summus Editorial, 2010.

MARTIN, Marcel. A linguagem cinematográfica. São Paulo: Brasiliense, 2005. Disponível em: <https://ayrtonbecalle.files.wordpress.com/2015 /07/martin-marcel-alinguagemcinematogrc3a1fica.pdf $>$. Acesso em: 14 set. 2016.

MONTIPÓ, Criselli. Jornalismo, ética e humanização: reflexões sobre a tríplicetessitura. In: CONGRESSO BRASILEIRO DE CIÊNCIAS DA COMUNICAÇÃO, 34., 2011. Recife. Intercom Sociedade Brasileira de Estudos Interdisciplinares da Comunicação. Recife, 2011. Disponível em:

<http://www.intercom.org.br/papers/nacionais/ 2011/resumos/R6-1228-1.pdf>. Acesso em: 19 jan. 2017.

PUCCINI, Sérgio. Documentário e roteiro de cinema: da pré-produção à pós produção. 2007. $236 \mathrm{f}$. Tese (Doutorado em Multimeios) Universidade Estadual de Campinas, Instituto de Artes, Campinas, 2007. Disponível em: $<$ www.bibliotecadigital.unicamp.br/document/?c ode $=v t \mid s 000439619 \& f d=y>$. Acesso em: 28 out. 2016.

SILVA, Luciene. O estranhamento causado pela deficiência: preconceito e experiência. Revista 
Brasileira de Educação, Rio de Janeiro, v.11, n.33, p. 424-434, 2006.

SINDICATO DAS INSTITUIÇÕES BENEFICENTES FILANTRÓPICAS E RELIGIOSAS DO ESTADO DE SÃO PAULO - SINBFIR. Declaração de Utilidade Pública. [s.d.]. Disponível em:

<http://www.sinbfir.org.br/juridico/164declaracao-de-utilidade-publica> Acesso em: 16 fev. 2017.

SOUZA, Gustavo. Fronteiras (in)definidas: aproximações e divergências entre documentário e jornalismo. Caligrama - Revista de Estudos e Pesquisas em Linguagem e Mídia, São Paulo, v.3, n.1, 2007. Disponível em: <https://www.revistas.usp.br/caligrama/article/v iew/64872>. Acesso em: 21 mar. 2018.

TAVARES, Denise. Fronteiras entre cinema e jornalismo. A realização de vídeodocumentário no curso de jornalismo. In: FÓRUM NACIONAL DE PROFESSORES DE JORNALISMO, 8., 2005, São Paulo. Anais... São Paulo: Universidade Metodista de São Paulo, 2005. p.1-17.

TRIVIÑOS, Augusto. Introdução à pesquisa em ciências sociais: a pesquisa qualitativa em educação. São Paulo: Atlas ,1987.

TV FACCOP ONLINE. Sonhos de Maio. 2017. (1h07m22s). Disponível em: <https://www.youtube.com/watch?v=qEEIKwZyj kA>. Acesso em: 21 mar. 2018.

YIN, Robert k. Estudo de Caso: planejamento e métodos. 4. ed. Porto Alegre: Bookman, 2010

Recebido para publicação em: 13/11/2017

Revisado em: 08/05/2018

Aceito em: 26/07/2018 